\title{
LA NUEVA GALERÍA DEL PARDO J. Pantoja de la Cruz, B. González y F. López
}

\author{
POR \\ MARÍA KUSCHE \\ Universidad de Bonn
}

\begin{abstract}
«Following the recent discovery of two related and identically sized portraits by Juan Pantoja de la Cruz which resulted part of the "Nueva Galería del Pardo", this paper recreates the content of the gallery. The gallery was commissioned by Philipp III to replace the "Antigua Galería del Pardo" conceived by Philipp II, and wich burned down in 1604. Juan Pantoja de la Cruz and Francisco López began to work on the new gallery in the same year, and it was completed in 1614 by Bartolomé González.

Its character was very different from that of the original gallery, and it effectively became a memorial to Philipp II, who was shown three times among his forefathers, his close family, children and grandchildren».
\end{abstract}

Hace sólo unos meses publiqué un artículo en el que traté de la juventud —hasta la fecha desconocida - de Juan Pantoja de la Cruz y también de algunos ejemplares de su obra madura y de algunas miniaturas ${ }^{1}$, completando con esto mi monografia de 1964 sobre el pintor. Entre otras obras presenté el magnífico retrato, sin duda al natural, del príncipe heredero de Saboya Felipe Manuel de 1604/1605 (Bilbao, Museo de Bellas Artes. fig. 1). No esperaba que, después de tan poco tiempo, llegase a mis manos otro retrato de importancia, desconocido, del artista, muy parecido en toda su presentación al de Felipe Manuel, esta vez de Felipe II (Madrid, Colección Particular, fig. 2). Estos dos hallazgos juntos me han hecho sospechar enseguida de que fuesen restos de la última gran obra de Pantoja: la nueva galería de retratos del Pardo que se creó por iniciativa de Felipe III al quemarse la antigua de Felipe II. Me han animado estos dos retratos a repensar toda la organización y temática de la nueva galería, ampliando, y a veces rectificando, unos breves apuntes míos antiguos sobre ella en mi monografía sobre Juan Pantoja de la Cruz ${ }^{2}$, e intentando reconstruirla como ya reconstruí la antigua galería en trabajos anteriores ${ }^{3}$.

1 M. Kusche, La juventud de Juan Pantoja de la Cruz y sus primeros retratos. Retratos y Miniaturas desconocidas de su madurez. AFA N. ${ }^{274}$, 1996, pp. 137-155.

2 M. Kusche, Juan Pantoja de la Cruz, 1964, pp. 103-109.

3 M. Kusche, La Antigua Galería de Retratos del Pardo I: su reconstrucción arquitectónica y el orden de colocación de los cuadros, AFA N. 253, 1991; La Antigua Galería de Retratos del Pardo II: su reconstrucción pictórica, AEA N.․ 255, pp. 262-292; La Antigua Galería del Pardo III: su importancia para la obra de Ticiano, Moro, Sánchez Coello y Sofonisba Anguissola y su significado para Felipe II, su fundador, AEA ‥ 257, 1992, pp. 1-37. 


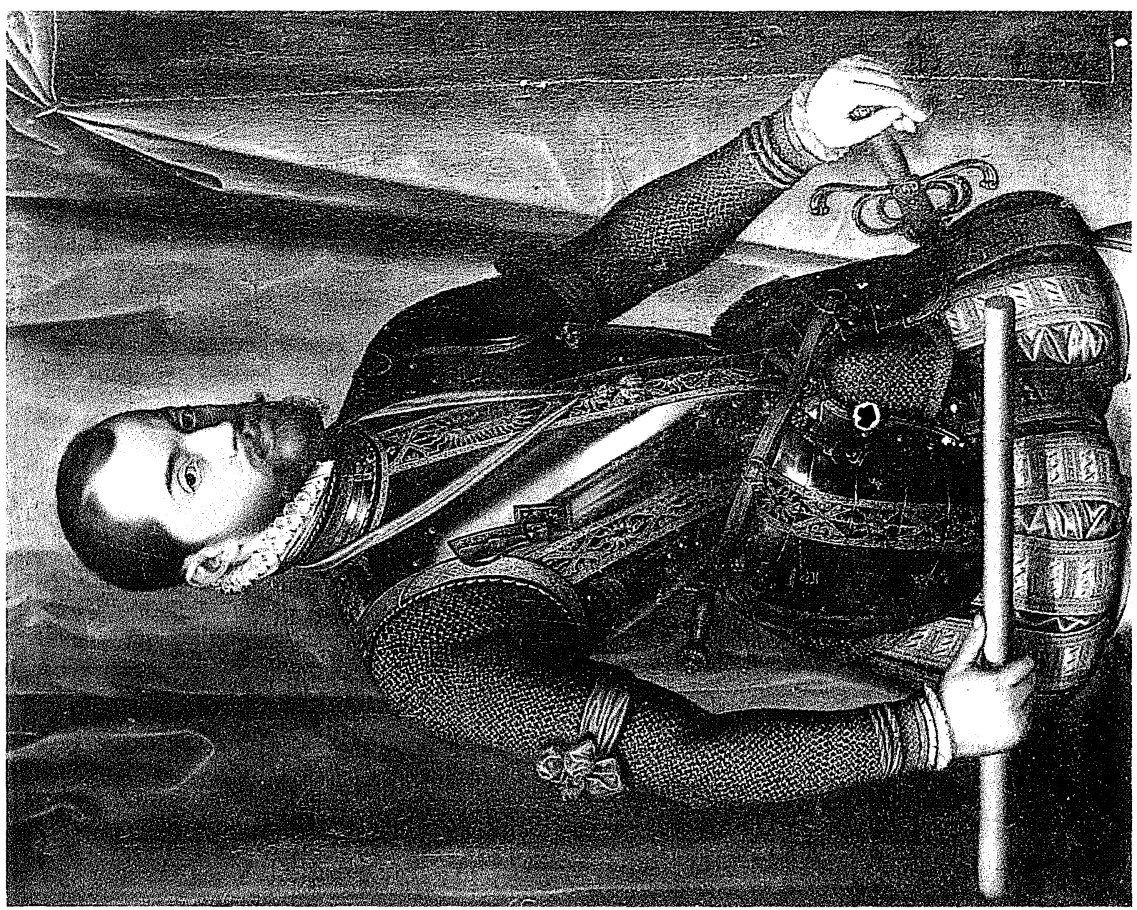

N

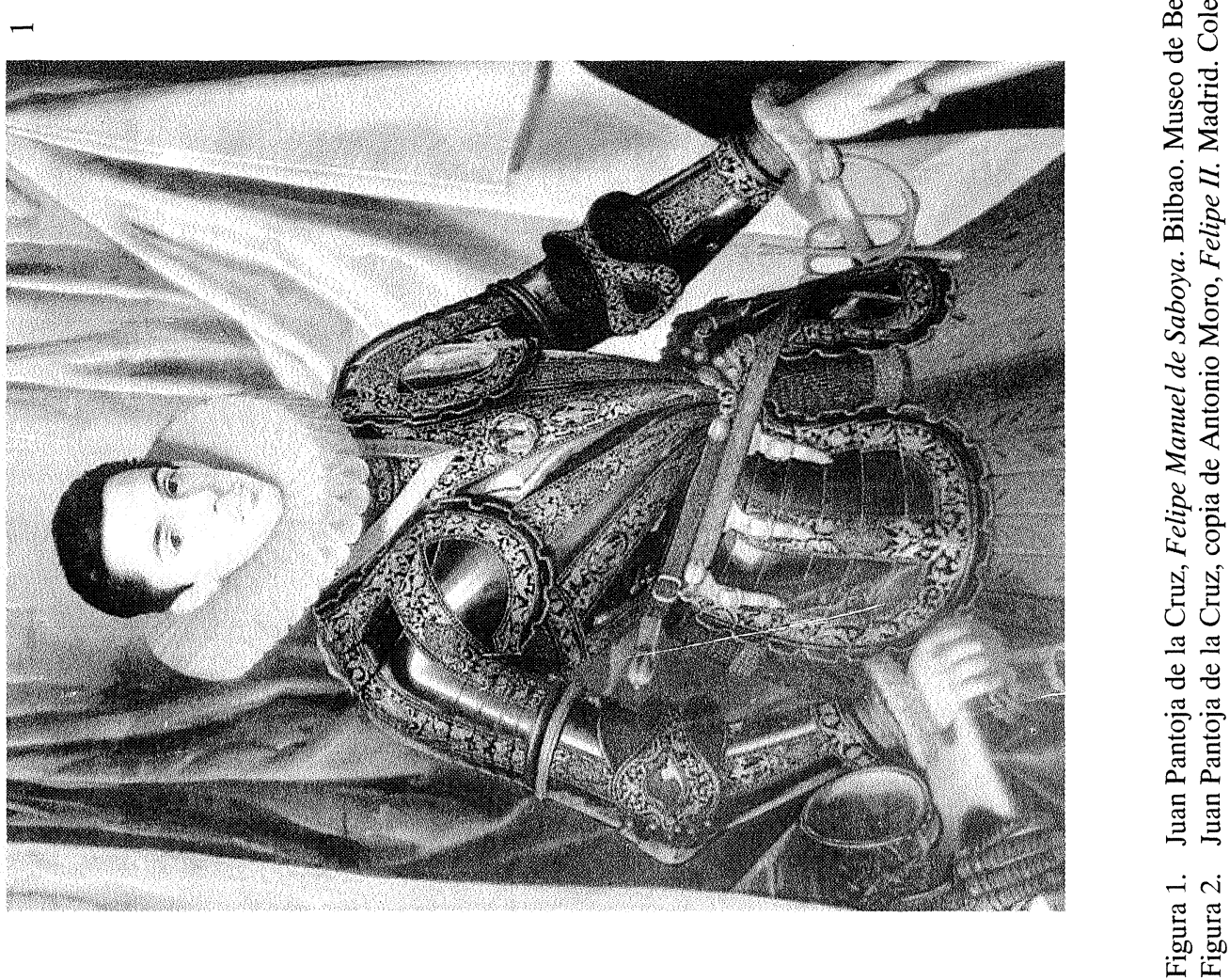


El retrato recién descubierto es una copia del retrato de Felipe II «en S. Quintín» por Antonio Moro. Indudablemente por toda su técnica y concepción el copista es Pantoja, y llama la atención que este retrato se asemeje por una cortina roja muy vistosa al mencionado del príncipe Felipe Manuel (fig. 1). Si además se observa que ambos retratos tienen las mismas medidas $(110 \times 90 \mathrm{~cm}$.) y que éstas son las que tenían los retratos de Pantoja de la nueva galería (incluyendo los marcos unos 120 x 110) —según se anotan en la «Memoria» de los retratos que Pantoja hizo para ella $-{ }^{4}$ la sospecha de que los dos retratos sean restos de la «Galería Nueva» se afianza y se transforma en certeza al ver que en la memoria se describe un retrato de Felipe II:

«de la edad de cuando fue de San Quintín, armado con mangas de malla y calzas blancas bordadas, la una mano sobre la espada y en la otra un bastón, con cortina y bufete carmesí».

El retrato de Felipe Manuel, seguramente por haber muerto, ya no figura en la lista de los retratos que Pantoja entrega para el Pardo, habiéndolo reemplazado por el del siguiente heredero, Victorio, también «armado y con cortina carmesí».

Cuando en 1604 se quemó la antigua galería con los magníficos retratos de Ticiano, Antonio Moro, Sánchez Coello y otros maestros (Vid. AEA n. ${ }^{\text {s }} 253$ y 255; 1991 y 257; 1992) Felipe III cortó los lamentos con un enérgico: «basta ya que lo demás se volverá a hacer» y le encargó inmediatamente a su pintor de cámara, Juan Pantoja de la Cruz, de emprender la tarea de la reconstrución de la galería. Ni se pudo ni se quiso hacer una réplica exacta de la antigua. Por un lado, porque la galería antigua — crecida en muchos años con retratos de familia y amigos, proveniente en gran parte de herencia - en su mayoría no se podía recuperar por no existir ya ejemplares de los mismos retratos para copiarlos, por otro también, porque ahora, al crearla nueva en su totalidad, Felipe III quería ajustarla a sus deseos y necesidades. Deseaba que esta galería nueva fuese expresamente de retratos «de la Real Casa de Austria» - como dice al final de la «Memoria» que presentaron los herederos de Pantoja, o de «Retratos de la invicta Casa de Austria» como dice Carducho ${ }^{5}$, título, que la vieja nunca pudo pretender al encontrarse en ella tantos personajes que, aunque unidos al Rey, no eran de su familia. Aquella galería vieja era la ilustración de una parte de la vida de Felipe II -incluyendo hasta sus pintores - pero nunca intentó que fuese una pura galería genealógica de la casa de Austria.

Por lo pronto, a Pantoja se le encargaron 35 retratos en vez de los 45 que contenía la antigua galería y también el fresco del techo, compartido éste con Francisco López. Los retratos, todos «hasta las rodillas» estaban destinados a los dos largueros de la sala. Los hizo Pantoja entre 1604 y 1608 —l año de su muerte—. Las paredes de la cabecera y del fondo quedaban libres. Algún tiempo después de su muerte le fueron encargados a Bartolomé González, 11 retratos más, los nueve hijos de Felipe III, más dos retratos de Felipe II y D. ํㅗㄱ Margarita. De estos retratos, aunque todos de las mismas medida que los anteriores, los de los Infantes eran de cuerpo entero, los de los reyes, como los retratos de los largueros, trescuartos, como habían sido todos los de la antigua galería.

4 R. de Aguirre, SEE. 1923, N. ${ }^{\circ}$ XXXI, p. 201, reproducido en M. Kusche, Juan Pantoja de la Cruz, Madrid, 1964, pp. 265-267.

V. Carducho, Diálogos de la Pintura, 1633, Edición Calvo Serraller, Madrid 1977, pp. 232-233. 
Tenemos 5 documentos que nos detallan estos encargos.

1) La mención del trabajo para la galería del Pardo, en el testamento de Pantoja de $1608^{6}$.

2) La «Memoria de los retratos que sean echo para la Casa Real del Pardo» que presentan los herederos de Pantoja en Palacio en 1612 al entregar los retratos, enlistándo y describiéndo todos (Véase documentos) ${ }^{7}$.

3) La «Memoria de los lienços de retratos que se entregaron a Antonio Ruiz cassero de las cassas reales del palacio de Valladolid ..., los cuales son para sacar las copias dellos para la cassa rreal del Pardo». Debe datar de 1604 cuando Pantoja empezó a reconstruir la galería. Estos retratos, que se entregaron al Guardajoyas Hernando de Espejo y que debían de volver a la Casa de la Ribera figuran también en el Inventario de 1612 que se hizo después de la muerte de la Reina Margarita ${ }^{8}$.

4) La memoria que presenta Bartolomé González con la lista de los retratos suyos de 1608-1617, que incluye los 11 que hizo para el Pardo, también con una descripción minuciosa. Por la edad de los Infantes parece que comenzó a trabajar en sus retratos por $1612^{9}$.

5) El inventario del Pardo de 1614-1617, «Sala de los Retratos» «Estos retratos hizo Juan Pantoja de la Cruz y los demás serán cargos viejos» ${ }^{10}$.

En el testamento de Pantoja del 7 de octubre de 1608 dice:

«Item digo y declaro que yo tengo una obra del Rey nuestro Señor a mi cargo en la casa real del Pardo; el techo della, que es la sala de retratos; y los retratos tengo yo sólo a mi cargo, en lo qual tengo hecha mucha cantidad y acabados algunos; si su majestad fuere servido que se continuen en mi casa como hasta aqui, y si no se tasen y si algo se me debiere dello se me pague. Y el techo que es de estuque y pintura al fresco la tenemos entre mi y Francisco López, pintor de su majestad, de la qual tenemos recibidos mill ducados: si Dios me llebare tasese mi parte de lo que tengo hecho, que bale más mi parte que la de Francisco López porque tengo trabaxado mucho más, y de los dichos mill ducados recibimos de por mitad y se cobre lo que más se me debiere. Item digo que entre mi y el dicho Francisco López se an hecho gastos en la dicha obra de que tengo quenta de lo que se a gastado, mando que se ajuste con él y se cobre lo que debiere, pagando de por mitad al albañil y al ama y a su mozo y alquiler de camas lo que pareciere deberseles hasta el dia que binieron del Pardo, pues gastó de por mitad.»

Este párrafo nos informa pues, que Pantoja tenia él sólo a su cargo los retratos y que el fresco del techo lo compartía con Francisco López. Del encargo de los retratos nos dice: «en lo cual tengo hecha mucha cantidad y terminados algunos, si u majestad fuere servido que se continúen en mi casa como hasta aqui y si no que se tasen y si algo se me debe dello se me pague...». Sin duda continuaron en su taller, ya que los herederos entregaron los 35 cuadros en 1612 en el Pardo y en la lista dice que se acabaron por orden de Miguel Reynalte su yerno.

No se habla del pintor que los terminó, pero parece probable que Bartolomé González, alumno de Pantoja y su sucesor como pintor de cámara y también sucesor en el trabajo de la galería, los terminase.

6 AHPM, Escribano Luis de Escaray, publicado en extracto por F.J. Sánchez Cantón en «Sobre la Vida y Obras de Juan Pantoja de la Cruz, AEA, ‥ 78, 1947, pp. 95; en extenso en M. Kusche, Juan Pantoja de la Cruz, Madrid 1964, p. 254.

7 APR, Carpeta Juan Pantoja de la Cruz, publicado por R. de Aguirre, SEE 1923, XXXI, pp. 201, reproducido íntegro en M. Kusche, Juan Pantoja de la Cruz, Madrid 1964, pp. 265-267.

8 APRM, Númeración General, leg. 902.

9 APRM, publicado por J. Moreno Villa, con notas de F.J. Sánchez Cantón, «Noventa y siete Retratos de la Familia de Felipe III por Bartolomé González», AEA N. 38, pp. 127-157, Pardo n. ${ }^{\text {os }}$ 23-33.

${ }^{10}$ APRM, Inventarios Reales. 
La lista completa de los retratos con sus descripcciones detalladas la tenemos en la memoria que presentan los herederos, de Pantoja después de su muerte en 1612. Entre ellos están los retratos de Felipe «de cuando fué de San Quintin» y un Principe de Saboya «armado ..con cortina carmesí y en la mano un bastón», es decir los retratos mencionados arriba.

Confrontando las descripciones de esta memoria con las de la lista de los diez retratos que existían en aquel momento en Valladolid y que se pusieron a disposición de Pantoja «para sacar copias de ellos» alrededor de 1604, vemos que efectivamente Pantoja los usó de modelos. De la mayoría de ellos hoy todavía se encuentran ejemplares. Se trataba de los siguientes retratos:

el Duque y la Duquesa de Saboya de Carraza, pintor de corte de Saboya (ejemplares hoy en la Galleria Sabauda, Turín),

la Reina Ana de Alonso Sánchez Coello (un ejemplar parecido existe en el Museo Lázaro Galdiano),

Felipe II de Moro «en la forma que estaba en San Quintin» (ejemplares en el Escorial; Berlin, Gemäldegalerie Dahlem; Kunsthistorisches Museum, Viena),

Juan de Portugal, también de Moro (ejemplar en Hampton Court),

D. ․ Juana de Moro de 1560 (Madrid, Prado),

Isabel Clara Eugenia del mismo Pantoja, «de mano de Juan de la Cruz» (ejemplar en Munich, Alte Pinakothek),

el Archiduque Ernesto «con calzas coloradas y el morrión sobre un bufete», probablemente de Martino Rota (Innsbruck, Schlo $\beta$ Ambras),

el Archiduque Matias «con calzas blancas», probablemente de Lucas van Valckenborch, éste y el último sin nombre de pintor,

el Archiduque Wencislao: «gran comendador y prior de Sta. Cruz, vestido de negro con habito grande en el pecho», según la descripción de Sánchez Coello (Ejemplar en Nelahozeve, Praga),

el Emperador Rudolfo «con tusón al cuello y la gorra aderezada» probablemente de Rota o Heintz (Innsbruck, Schloß Ambras).

Para los demás retratos Pantoja seguramente encontró modelos en los fondos del Alcázar que él mismo había inventariado.

Según las descripciones de la «memoria» de Pantoja:

los de Carlos V y la Emperatriz estaban claramente copiados de Tiziano (Monasterio del Escorial, Museo del Prado),

el de Felipe II joven, que seguía al de sus padres, vestido de negro, fue copiado de Tiziano (Madrid, Museo del Prado) o de Lucas de Heere (Toledo, Colección Particular),

el retrato de María de Portugal era el único retrato conocido de la Princesa. Aún existe copia en Viena (Kunsthistorisches Museum),

el de Isabel de Valois era copia del de Sofonisba (versión trescuarto, seguramente la que se encuentra aún en el Museo del Prado, que más o menos se ajusta a las medidas de los dos retratos mencionados al principio, o una similar),

el de María Tudor se hizo según el de Moro (Museo del Prado),

el de Don Carlos era copia también de Sofonisba (ejemplares en varias colecciones españolas y también en Viena, Kunsthistorisches Museum),

los de los Infantes Don Fernando y Diego se hicieron según retratos de Sánchez Coello; del «en silla bordada» — silla infantil— de Fernando, ya no existe ejemplar, el de Diego conviene con la descripción de un retrato que se suele tener por Fernando (Madrid, Descalzas Reales), 
los de Felipe III, armado, (Viena, Kunsthistorisches Museum), así como también el de la Reina Margarita (Madrid, Valencia de Don Juan) parece que eran réplicas de originales del mismo Pantoja. El del Valencia de Don Juan sólo difiere de el del Pardo en cuanto le falta la cortina,

los retratos del nuevo príncipe heredero de Saboya, Victorio, que ocupó el puesto de su hermano Felipe Manuel, y el del próximo en edad, Filiberto, serían originales de Pantoja, podemos suponer que serían parecidos al del primogénito que conocemos (Bilbao, Museo de Bellas Artes).

$\mathrm{Al}$ agrupar estos retratos según el orden de «la Vieja Galería» —que al principio le debió servir de modelo a Felipe III es decir 18 y 17 retratos respectivamente en cada lado-, hubiese resultado la siguiente galería:

Primera versión de la galería nueva según los retratos de Pantoja (comenzando en el extremo superior)

lado izquierdo:
Fernando el Católico
Isabel la Católica
su hijo Don Juan
Felipe el Hermoso
D. Juana
el Emperador Carlos
la Emperatriz
Felipe II
María de Portugal
Isabel de Valois
María Tudor
Ana de Austria
otro de Felipe II
Don Carlos
Don Fernando
Don Diego
Don Felipe III
La Reina D.ํa Margarita

lado derecho:
María de Ungría
Leonor Reina de Francia
Don Juan de Austria
Don Sebastián
D.․ María, Emperatriz de Alemania
D. Juan de Portugal
D. Juana de Portugal
el Archiduque Ernesto
el Emperador Rudolfo
el Emperador Matías
el Emperador Maximiliano
Filiberto de de Saboya
Victorio de Saboya
la Infanta Catalina Micaela
el Duque de Saboya
la Infanta Isabel Clara Eugenia
el Archiduque Alberto

La concepción está clara: se remontaba la genealogía hasta los Reyes Católicos —en la galería vieja sólo había llegado a Carlos $\mathrm{V}$ - y después se iba presentando pareja por pareja seguida de los respectivos hijos. También viendo las correspondencias de un lado al otro se observa que se trataba de un orden muy bien estudiado: en frente de Felipe III y Margarita caía la pareja de los regentes de los Países Bajos - Isabel Clara Eugenia y Alberto- en frente del primer retrato de Felipe II se colocaba el de su hermana D. ${ }^{\underline{a}}$ Juana, en frente del del Emperador Carlos el de su hermana la Emperatriz María.

De quedar así esta galería de copias hubiese resultado no tan importante artísticamente como la vieja, pero muy completa e interesante genealógicamente. 
Del tema del techo sólo tenemos una noticia que además demuestra que pronto pasa la fama. Sólo unos 25 años después, Vicente Carducho ya no se acuerda de la autoría de Pantoja y sólo nombra en relación a la nueva galería a Bartolomé González y a Francisco López. Dice:

«La pieza adonde se viste su Majestad, es de retratos de la invicta Casa De Austria, de mano de Bartolomé Gonzalez; la cubierta de ella es de estuques y pintadas algunas vitorias del Emperador Carlos V que pintó Francisco López.» 11

Por lo menos nos enteramos así, que el tema del techo, compartido entre Pantoja y Francisco López, como sabemos por el testamento del primero, se relacionaba con el de los retratos. Pero más bien que de una apoteósis de Carlos V, como parece que lo comprendió Carducho, se debió tratar de una apoteósis de la Casa de Austria en general, según podemos juzgar por el tema de los retratos y por los restos de la parte occidental del techo, recientemente descubiertos. La parte descubierta del fresco, muy rica en colorido y dorados, está dividida en casetones, recuadros y tondos, con escenas que representan la rendición de Granada y grupos de guerreros ${ }^{12}$. Esperemos que se descubra el resto para obtener una visión completa.

En cuanto a los retratos de Bartolomé Gonzalez:

Parece probable, como vimos, que Bartolomé González acabara los retratos que el maestro Pantoja había planteado y no pudo terminar. Felipe III mientras tanto debió haber decidido cómo completar la galería y, por lo visto, directamente después de estar terminada la serie de Pantoja en 1612, según se ve en la memoria de González de 1608-1617, le encargó en 1612 a González retratos de sus nueve hijos y —no sabemos si al mismo tiempo o después- otra pareja de retratos de sus padres, Felipe II y D. a Ana. Con esto se encargaban los 11 retratos que faltaban para acabar la galería al estilo de la galería vieja, pero dándole más simetría: 18 para cada uno de los dos lados largos (uno más en el lado del patio que en la galería vieja), 5 para la cabecera y los pies respectivamente. En todos los retratos de Infantes, menos en los dos de los prometidos franceses del Príncipe Felipe y la Infanta Ana Mauricia, el pintor anota «original», en los de los reyes «copia».

Sin embargo, parece que Felipe III, mientras se iban pintando los retratos de los Infantes, ya no estaba satisfecho con este orden y mandó que se eliminaran algunos retratos de Pantoja. En el Inventario del Pardo de 1614 consta que había en la sala de retratos «tres más de los 35 que hizo Juan de la Cruz». Pero aquí hay un error: los personajes alistados no son más que 37, es decir había en número sólo dos más que en la lista de Pantoja. El que escribió esto además no sabía que los personajes habían cambiado en relación a los de Pantoja: aquí ya están incluidos los 9 hijos de Felipe III y Margarita de Austria por González y ya se han retirado 7 retratos de Pantoja: el de la Emperatriz Isabel, los de los Príncipes de Saboya, del Archiduque Ernesto, de Juan de Austria, de las Reinas Leonor y María.

Según este inventario de 1614 el orden definitivo del larguero izquierdo permaneció como estaba planeado con Pantoja, con una exepción, se suprimió el retrato de la Emperatriz Isabel. A los 17 retratos que así quedaban en este lado parece que se les aumentó por los retratos de los príncipes herederos, los Infantes Felipe (IV) y de Isabel de Borbón, que son los que en la lista del inventario le siguen a los de los Reyes Felipe y Margarita, obteniéndose así 19 personas para este lado.

11 Véase Nota 5

12 F. Marías, El Palacio Real del Pardo de Carlos V a Felipe III, Reales Sitios XXV, Aniversario 1989, pp. $137-146$ 
En el larguero derecho hubo mayores cambios en relación con la lista de los herederos de Pantoja y se ordenan de otra forma algunos retratos de él. Se colocaron los restantes 7 retratos de los hijos de Felipe III por Bartolomé González después de los de las hermanas del Rey y sus cónyugues y se suprimieron los retratos que ya mencionamos arriba, resultando en total 18 retratos, uno menos que en el lado derecho - como en la antigua galería - seguramente debido a alguna diferencia en los tamaños o en la arquitectura.

Así aún quedaban libres los dos extremos, que seguramente estaban pensados para los retratos de Felipe II y D. a Ana. Éstos no están todavía en el Inventario de 1614, pero sí aparecen en las adiciones al de 1617 y en la cuenta de Bartolomé González de los retratos que hizo entre 1608 y 1617. Por lo visto estos dos estuvieron entre los últimos que el pintor entregó, junto a otras obras para el Rey. Aunque llegaron con retraso, no hay duda que también estaban destinados a la galería. Es más, el hecho de que se pintaron como los últimos indica que con ellos el Rey culminaba, cerraba, la disposición de la sala. Probablemente estaban colocados, como dijimos, cada uno en uno de los lados estrechos, uno enfrente del otro (como estuvieron los de Felipe II y Isabel de Valois en la antigua galería), o también tal vez los dos juntos en la cabecera. Que hubiesen estado agrupados cada uno con dos parejas de nietos en los dos extremos de la sala hasta llegar al número de 5 retratos respectivamente como los tenía la galería vieja, hay que excluirlo. Porque entonces los largueros hubieran quedado muy espaciados y no hubiese tenido sentido que se suprimieran anteriormente los 7 retratos mencionados de Pantoja. Además a Felipe II en este caso le hubieran correspondido su nieto -el heredero- con su mujer francesa y también su nieta Ana Mauricia con el futuro rey de Francia, y éste hubiese estado presidiendo junto al «Rey Viejo» «la Invicta Casa de Austria», lo que parece impensable.

Al comparar las descripciones de las diferentes partidas de retratos de Infantes de 1612 en la memoria de Bartolomé González, así como los retratos dobles existentes aún para Viena, (Castillo de Ambras, Innsbruck), con las descripciones de los retratos de los Infantes del Pardo, se realiza que éstos se diferenciaban bastante de los primeros. Los del Pardo tenían mayor aplomo - una manera más oficial de presentar a los Infantes- como correspondía al carácter ejemplar de la galería. Los dos príncipes mayorcitos Don Felipe (IV) y Don Carlos estaban armados, los dos su con su bastón de mando y al lado de su morrión. Don Fernando iba de vaquero pero con una daga en la mano, sólo Don Alonso, existente aún (fig. 5), lo vemos como niño pequeño en su carrito, pero también le da categoría representativa la expresión seria de su cara, la posición derecha del carrito, las cortinas de su cama que le circundan como un dosel, todo muy distinto al bebé rollizo que se ve en este caso lo mismo en Viena que en Valencia. Las Infantas Ana Mauricia y Margarita llevaban cada una un abanico en la mano como damas adultas. Contrastan pues con los retratos de 1512 para Flandes y Viena en que los tres Infantes Felipe Carlos y Fernando van vestidos de blanco, las manos en las espadas y en las gorras, las Infantas Ana y María con pañuelo o libro de horas y de pie sobre un suelo enlosado. Sin embargo los retratos del Pardo se parecen según sus descripciones bastante a otros retratos dobles de los Infantes que se encuentran en el Instituto Valencia de Don Juan (figs. 4, 5 y 6). Y éstos aunque también son variaciones de los de Flandes y Viena (aparte de que falta el Infante Fernando) parecen ya algo posteriores según se ve en las figuras de los Infantes mayores. La cara de Felipe (IV) armado con bastón parece más marcada, así como también la figura de Carlos más espigada y consciente. También el porte de las Infantas, de Ana Mauricia y María ya recuerda el de damas adultas, con sus abanicos, que también llevaban en los retratos del Pardo. Margarita en su retrato del Valencia también está acompañada de su perro como lo estaba en el Pardo. Alonso en ambos lados está presente en su carretón. 


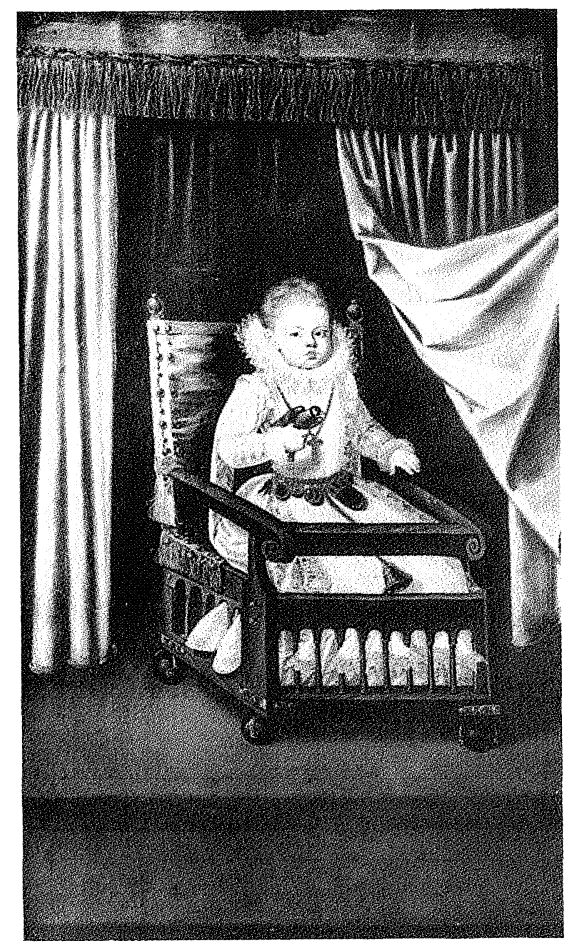

4
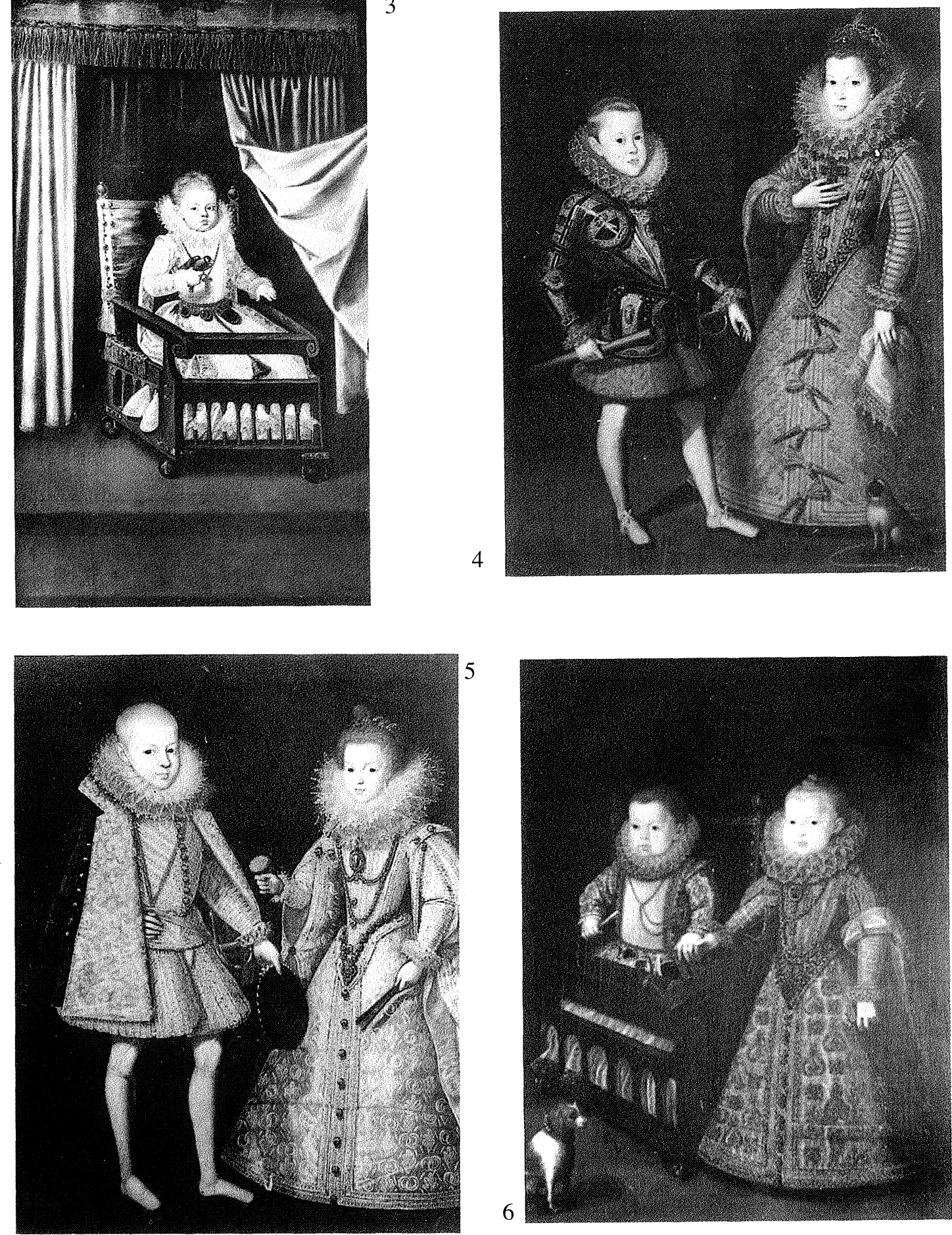

Figura 3. Alfonso el Caro.

Figura 4. Los Infantes Felipe IV y Ana Mauricia.

Figura 5. Los Infantes Carlos y María.

Figura 6. Los Infantes Alonso y Margarita.

Bartolomé González, Madrid. Instituto Valenciano de Don Juan. 
Si se compara la edad de lo niños del Valencia y del Pardo frente a los retratos de los Infantes de Viena de 1612, no sólo hay un cambio en las vestimentas y posturas sino también se ve una clara incongruencia entre la relación de edad de Alonso y los Infantes mayores ${ }^{13}$. Ésta se explica fácilmente. La serie de Infantes para el Pardo se debió hacer ya muy cerca de la fecha de entrega en 1614. Convenía mostrar a los Infantes en el Pardo algo más mayorcitos, en una edad de mínima compostura. Alonso, nacido en octubre del 1611, muerto en octubre del 1612, en esta fecha por lo tanto ya no vivía. Como al pequeño difunto no se le quería excluir de la galería, se le presentó así como González lo había retratado en 1612, poco antes de su muerte.

Los retratos de Infantes del Valencia de Don Juan Felipe (IV) y Ana Mauricia (fig. 4), así como Carlos y María (fig. 5) y también Alonso y Margarita (fig. 6), dan una idea de cómo serían los retratos de infantes de Bartolomé González del Pardo. Ante todo lo hace naturalmente el original de Alonso el Caro con su carretilla que es el único retrato que muestra directamente la mano de González (Madrid, Colección particular, fig. 3). Coincide en el ancho con los del Pardo, y lo hace en el largo si se descuenta una tira que visiblemente lleva añadida. Se ve al niño exactamente como lo describe la memoria de González:

«Item otro retrato del Srmo Infante Don Alonso, vestido de tela azul,con su guanición de caracolillos de plata, y puntillas, con sus dijes de oro, y en la mano un pajarito, metido en su carretón. Es asimismo entero y el tamaño de los demás.»

Los dos retratos de Felipe II y Ana de Austria en la lista de Bartolomé González se describen de la forma siguiente:

«Item un retrato del Rey nro. Sr. que está en el cielo. Copia. Con armas grabadas y calzas carmesies, con pasamanos de oro y entretelas blancas. La una mano en un bastón, la otra en la espada, y una celada sobre un bufete. Del mismo tamaño. Para el Pardo.»

«Mas otro retrato de la Sma. Reina Da. Ana, vestida de raso blanco, acuchillado y guarniciones bordadas, con sus puntas, collar y cintura de joyas grandes de diamantes. Las mangas encarnadas, bordadas. La una mano sobre una silla y en la otra un pañuelo. Copia. Del mismo tamaño. Para el Pardo.»

Estos dos fueron por lo tanto copias variadas de retratos de Sánchez Coello que éste había pintado poco después de la boda de Felipe y Ana, como el del Rey Felipe II en Glasgow (Pollok House, fig. 7) y el de la Reina Ana en el Lázaro Galdiano (Madrid, fig. 8).

¿Qué aportaba cada uno de los tres pintores?

El mérito artístico de Pantoja, aparte de los retratos de Felipe III y D. Margarita, originales suyos, se centraba en la calidad de sus copias. Según vemos en el retrato de Felipe II, copiado de Moro, la calidad de estas copias era magnífica pero además tenían el aire personal del pintor. Las variaba según el tamaño lo exigía y le daba con sus cortinajes y paisajes ese carácter más ornamental del que ya hemos hablado. Mayor creatividad podría poner Pantoja en los frescos del techo, así como también tuvo esta oportunidad Francisco López. Bartolomé Gonzalez sin duda hizo el esfuerzo artístico mayor, creando unos retratos de Infantes que al mismo tiempo cumplían con el carácter representativo de la galería y además tenían el encanto ingénuo de sus retratos infantiles.

13 J. Moreno Villa, con notas de F.J. Sánchez Cantón, «Noventa y siete Retratos de la Familia de Felipe III por Bartolomé González», AEA N. 38, pp. 127-131. «G. Heinz und Karl Schütz», Porträtgalerie zur Geschichte Österreichs von 1400 bis 1800 Viena 1976, p. 78, n. ${ }^{\circ}$ 39, fig. 121 ; p. 79, n. ${ }^{\circ} 40$, fig. 122; p. 83, n. ${ }^{\circ} 45$, fig. 123. 
La galería por múltiples causas se ha ido dispersando. Repitamos lo que se ha conservado en total de retratos provenientes del Pardo:

Por el momento sólo conocemos cuatro retratos que nos pueden dar una idea palpable de aquella galería: tres de mano de Pantoja: el de Felipe II «en la batalla de S. Quintin» (fig. 2) y el del Duque de Saboya (fig. 1) y con toda probabilidad también el de Isabel de Valois según Sofonisba Anguissola (Madrid, Prado), y de Bartolomé González el de Alonso el Caro en carretilla (fig. 3).

La Galería definitiva, con los retratos de Pantoja y Bartolomé González, resultaría pues, según todo lo dicho, de la siguiente forma:

\section{Versión definitiva de la galería nueva con los retratos de Pantoja y González} (comenzando en el extremo superior)

lado izquierdo:

Fernando el Católico

Isabel la Católica

el Infante D. Juan

Felipe I

D. uana

El Emperador Carlos V

Felipe II

la Reina portuguesa

la Reina inglesa

la Reina D. Isabel

la Reina D. ${ }^{\prime a}$ Ana

el Rey Felipe II

el Príncipe D. Carlos

el Príncipe D. Fernando

el príncipe D. Diego

Nuestro Señor D. Felipe III

la Reina D. ․ Margarita

el Príncipe Felipe (IV)

Madame Isabela (Borbón) lado derecho:

Felipe II

\author{
el Rey D. Sebastián \\ D. Juan de Portugal \\ Princesa D. uana \\ el Emperador Matías \\ el Emperador Rudolfo \\ la Emperatriz María \\ el Emperador Maximiliano \\ el Duque de Saboya \\ la Infanta D. atalina \\ el Archiduque Alberto \\ la Infanta D. ․ Isabel \\ el Infante Alfonso el Caro \\ la Infanta D. ${ }^{\mathrm{a}}$ Margarita \\ el Infante D. Fernando \\ el Infante D. Carlos \\ la Infanta D. aㅗía \\ el Rey de Francia (Luis XIII) \\ la Infanta D. ․ Ana (Mauricia)
}

D. ${ }^{\mathrm{a}}$ Ana

Resumiendo la concepción y la presentación final de la nueva galería:

$\mathrm{El}$ hecho de que se encargara un tercer retrato de Felipe II parece lo más significativo del nuevo orden y muy revelador para toda la personalidad de Felipe III. Con este tercer retrato de Felipe II la galería definitivamente se dedicaba al gran padre y al abuelo de toda esta fila de hijos y de infantitos pequeños que demostraban su corta edad porque el tamaño de cuerpo entero les cabía en el mismo espacio que a los mayores sólo les admitía el medio cuerpo. Ya en la lista de Pantoja, donde Felipe II aparece dos veces, se ve que Felipe III desde el principio le dio más importancia a la figura de su padre que a toda la restante familia. Pero no le bastó tener presente a Felipe II como hijo del Emperador y después como esposo y padre, sino deseaba verlo en la galería expresa y especialmente como padre suyo, esposo de su madre D. ․ Ana de Austria, y abuelo de sus hijos. 


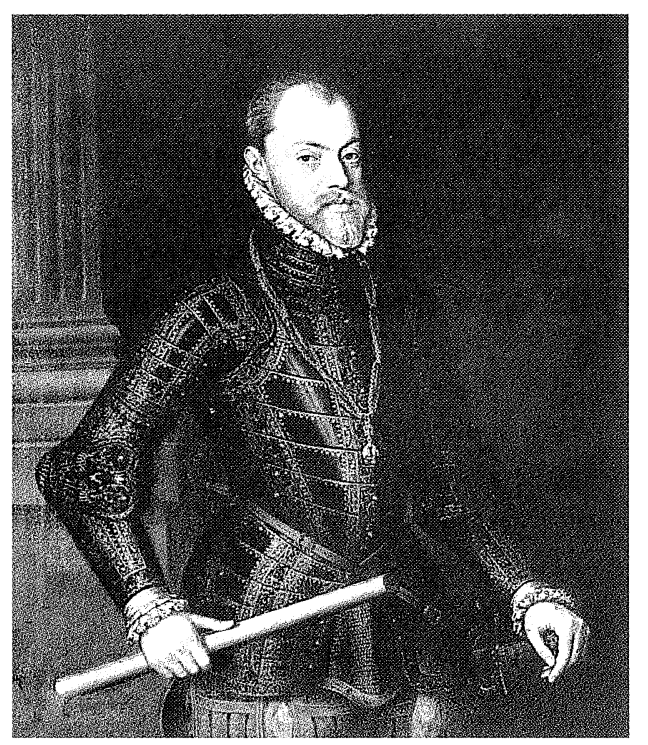

$7 \quad 8$
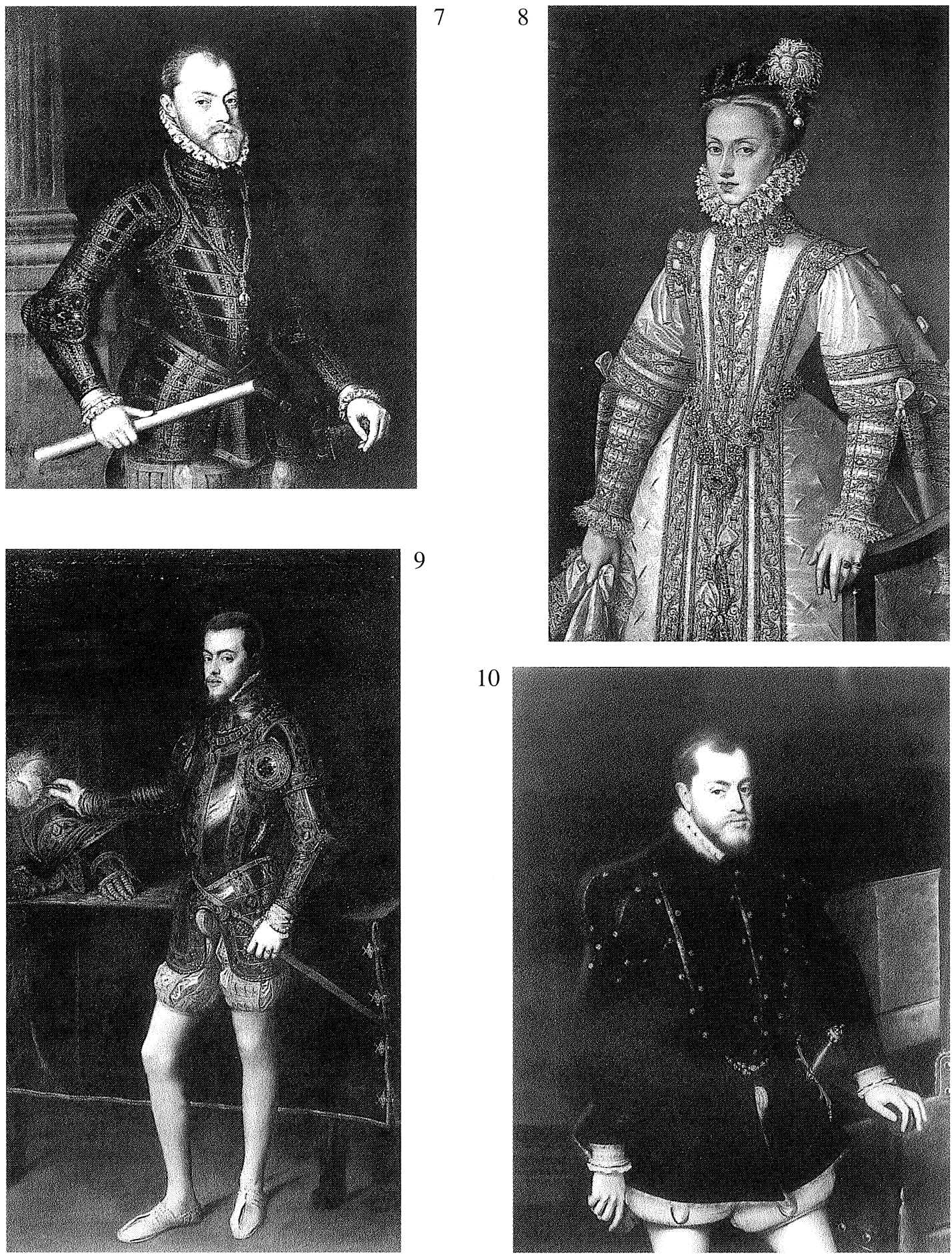

10

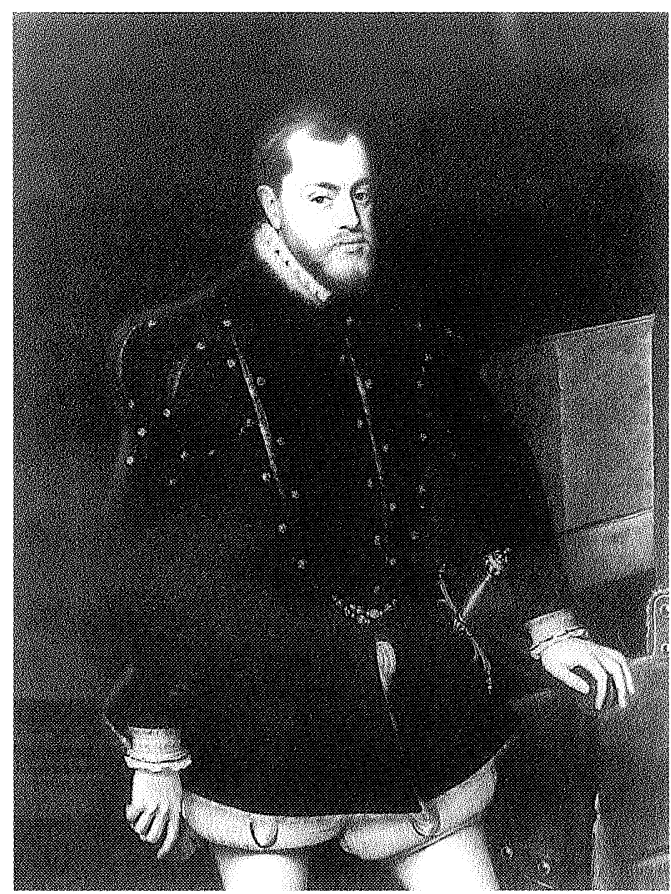

Figura 7. Alonso Sánchez Coello. Felipe II. Glasgow Pollok House.

Figura 8. Alonso Sánchez Coello. Ana de Austria. Madrid. Museo Lázaro Galdiano.

Figura 9. Tiziano. Felipe II. Madrid. Museo del Prado.

Figura 10. Lucas de Heere. Felipe II. Toledo. Colección particular. 
Nos podemos hacer una idea de ellos por ejemplares originales. El primer retrato de $\mathrm{Fe}-$ lipe II, Felipe como hijo, como príncipe, Pantoja lo pintó, como ya dijimos, copiando o de Ticiano (fig. 9) o de Lucas de Heere (fig. 10). Se encontraba al lado del su padre Carlos V en copia también de Ticiano armado con bastón de mando, como la que existe de Pantoja en el Monasterio del Escorial en la biblioteca.

El segundo retrato de Felipe II - Felipe rey, el retrato aún existente- ya hemos visto que Pantoja lo tomó del modelo de Antonio Moro de «cuando fue de S. Quintín» (fig. 2). Estaba colocado entre los retratos de sus esposas (de los que parece que se ha conservado el de Isabel de Valois en Madrid, Museo del Prado) y de sus hijos herederos de la corona.

El tercer retrato de Felipe II como padre de Felipe III, esposo de su madre Ana de Austria y abuelo de sus hijos, y también el retrato de ésta, como anotamos, fueron copias de retratos de Sánchez Coello como el del Rey Felipe II en Glasgow (Pollok House, fig. 7) y el de la Reina Ana en el Lázaro Galdiano (Madrid, fig. 8) y presidían en las filas de familiares y nietos (parecidos a los del Museo Lázaro Galdiano, Madrid figs. 4, 5 y 6) entre ellos el aún existente (Madrid, Colección Particular, fig. 3).

«La Galería Nueva de retratos del Pardo», de Felipe III, que comenzó queriendo ser una galería de «La invicta Casa de Austria», acabó pues por ser una galería por lo menos tan personal como lo había sido la vieja de Felipe II: Felipe III reduce en la galería el número de los retratos antiguos de la familia para hacerle sitio a los retratos de todos sus hijos, vivos o ya muertos. Pero ante todo da la impresión que se los presenta a su padre, convertiéndose la sala, con la triple presencia de éste, en un gran homenaje al Rey Viejo.

En presentación y carácter también se diferenciaba la «Galería Nueva» de la vieja. En los retratos ya no bastaba la severidad y sencillez que los originales tenían, sino que éstos se modernizaron enriqueciéndose con abundantes cortinajes - como esos flamantes rojos que vimos al principio en los retratos del Príncipe de Saboya y Felipe II, de los que partimos-. Donde no había cortina había «pais», es decir un fondo de paisaje y también recobraban importancia los distintos atributos: los muebles, los atributos personales. Además rompían con la uniformidad y gravedad del conjunto de los mayores las figuritas graciosas de cuerpo entero de los infantes. Fue pues el espíritu de esta galería nueva ya bastante barroco y se alejaba de la antigua no sólo por su nuevo programa sino también por su carácter más movido y pomposo.

\section{Documento}

(Archivo del Palacio Real, Carpeta Juan Pantoja de la Cruz).- Publicado por R. de Aguirre, Soc. Esp. Exc. 1923, XXXI, 201.

Memoria de los Retratos que sean echo para la Casa Real del Pardo, son los siguientes:

Primeramente seyço un retrato del Rey Don Fernando pintado en lienço de bara y media de alto y vara y cuarto de ancho. bestido de terciopelo morado y mangas carmesíes, todo bordado de plata y oro, cortina de brocado, bufete y espada con tafetin./ Mas otro retrato de la Reyna Doña Isabel la Catolica del mismo tamaño, vestida de terciopelo carmesi, mangas de tela amarilla bordado por el canto, cortinas de brocado. Arrimada a una bentana con un pais./ Mas otro retrato del Pe.Don Juan su hijo, bestido de terciopelo carmesi con su rropa verde bordado el canto, la mano sobre la cabeza de un perro, cortina morada de damasco./ Mas otro retrato del Rey Don Felipe el primero bestido de un sayo berde con mangas acuchilladas y ropa morada bordada con su tuson de oro y en la mano unos guantes, con un pais./ Mas otro retrato de la Reyna Doña Juana su muger bestida de morado bordadas las guarniciones con joias, y en la mano un panizuelo y la otra en una silla con guantes./ Mas otro retrato del $\mathrm{Em}$ perador Carlos quinto armado con cortina y bufete carmesi y una corona imperial encima, con un pais./ Mas otro 
retrato de la Emperatriz su muger bestida de morado bordadas las guarniciones y mangas blancas, sentada, y en la mano unas oras./ Mas otro retrato del Rey Don Felipe segundo siendo principe bestido de negro a lo antiguo forrado en armiño con botones de oro, la una mano sobre un bufete y en la otra guantes con pais./ Mas otro retrato de la Princesa de Portugal su primer mujer, bestida de encarnado bordadas las guarniciones, sentada, en las manos guantes y lienzo, con joias de rubies y perlas./ Mas otro retrato de la Reyna Doña Isabel bestida de terciopelo negro con joias, y la mano en una silla, con una mano prendida de una cadena, con cortinas de brocado arrimada a una silla./ Mas otro retrato de la Reyna Doña Maria bestida de morado, sentada en una silla bordada, con una xoia grande en el pecho y en las manos unos guantes y una rosa./ Mas otro retrato de la Reyna Doña Ana bestida de blanco acuchillada y raso pardo, con joias cortinas carmesi y un paniçelo y guantes, con bufete y cortina./ Mas otro Retrato del Rey Don Felipe segundo de la edad de cuando fué de San Quintin armado con mangas de malla y calças blancas bordadas, la una mano sobre la espada y en la otra un bastón con cortina y bufete carmesi./ Mas otro retrato del Pe Don Carlos todo bestido de blanco forrado en lobos blancos, con su espada de oro esmaltada, en la mano un guante colorado, y en la otra metida en la guia, con cortina azul./ Otro retrato del Principe Don Fernando sentado en una silla bordada, bestido de encarnado bordado de plata, con un bufete morado y encima un relox y una gorra con xoias y plumas./ Mas otro retrato del Pe. Don Diego entero bestido con calças amarilla y una cuera de ambar con botones de oro y su espada y una bara en la mano./ Mas otro retrato del Rey Don Felipe tercero armado con calzas blancas bordadas, con bufete y cortina carmesi un baston en la mano y la otra sobre un morrión./ Mas otro retrato de la Reyna Doña Margarita bestida de raso blanco prensado con joias de diamante, en la silla una mano y en la otra un abanico, con cortina carmesí./ Mas otro retrato del Archiduque Alberto armado, con calças azules, debajo de una tienda carmesi la una mano en la cinta y en la otra un baston./ Mas otro retrato de la Serenisima Infanta Doña Isabel (su mujer) bestida de negro bordado de acero con joias en la una mano un retrato del Rey Don Felipe tercero y la otra en una silla con una cortina./ Mas otro retrato del Duque de Sabo$y a$ armado, con un baston en la mano con calzas amarillas bordadas, arrimado a una silla, con un pais./ Mas otro retrato de la Infanta $\mathrm{Da}$. Catalina bestida de negro con mangas pajisas bordadas y joias, con cortina, y la mano en el pecho./ Mas otro retrato del Pe. Victorio armado, con calzas moradas bordadas y cortina carmesi y en la mano un baston./ Mas otro retrato del Pe Filiberto armado, con calzas carmesi y cortina berde rebuelta y una columna y la mano sobre la espada y otra sobre un morion, questa sobre un bufete./ Mas otro retrato del Emperador de Alemania Mascimiliano bestido con cuera, acuhillada y folladas blancas y boemio negro forrado en lobos blancos, la mano con guante sobre la espada con cortina de brocado./ Mas otro retrato del Emp. Matias con coleta de ambar y botones de oro y jubon de tela blanca calzas blancas, con capa negra echada por debajo del braço, la mano en la espada, con cortinas carmesi./ Mas otro retrato del Emp. Rodolfo bestido con cuera y calzas blancas bordadas, con botones de oro redondos y el collar del tuson, la mano en la espada y la otra los guantes, con cortina de brocado./ Mas otro retrato del Archiduque Ernesto armado, con calças encarnadas bordadas y la una mano sobre una celada y la otra en la espada./ Mas otro retrato de la Princesa Da. Juana bestida de negro picado y prensado bordadas las guarniciones de seda, con la una mano un paniçelo y la otra en la silla de terciopelo negro con cortina./ Mas otro retrato del Pe. De Portugal su marido bestido de carmesi bordado de oro y un boemio negro bordadas las guarniciones forrado en martas./ Mas otro retrato de la Emperatriz Da. Maria de Alemania bestida de terciopelo negro con puntas de oro y cristal, en la una mano unas oras y en la otra unos guantes, arrimada a un bufete carmesi, con sus cortinas de terciopelo carmesi./ Mas otro retrato del Rey D. Sebastian armado con calças blancas bordadas y un baston en la mano la otra en la espada con guante de malla, con un pais./ Mas otro retrato del Sr. Don Juan armado con calças carmesi mangas de malla la mano sobre un león./ Mas otro retrato de la Reyna Leonor con tocas de biuda bestida de negro, hermana del Emperador Don Carlos./ Mas otro retrato de la Reyna Maria asimismo ermana del emperador, bestida de negro con tocas de biuda y unas oras en la mano.

Todos de un tamaño y corresponde el uno al otro./ Firmado por Jacques Le Mucq Arquero y Concerje de la Casa Real del Pardo a 4 de Diciembre 1612.

Decimos nos Andres Lopez y $\mathrm{P}^{\mathrm{z}}$ de Guzman pintores, Andres Lopez nombrado por parte de los erederos y testamentarios de Ju de la pintor de Camara de su Magd. ya difunto y el dicho $\mathrm{P}^{\mathrm{z}}$ de Guzman pintor de S. Mag. nombrado por Hernando Despejo guarda joyas del Rey nro Sr. para tasar los treynta y cinco Retratos de la Real Casa de Austria que tomó para hacer a su cargo el dicho Ju de la y se acabaron por orden de Miguel de Reynalte su yerno y abiendolos listo para tasallos parte de ellos en el Pardo y parte en Madrid en cargo de nros conciencias nos parece que estan bien echos y acabados a nuestra satisfacción y porque entrellos ay dibersos precios unos mas y otros menos Repartidos entre todos igualmente bien a salir a sesenta y cinco cada uno que suman... todos los dichos treynta y cinco Retratos dos mil y ducientos y setenta y cinco ducados y en esto nos conformamos y juramos a Dios y a esta $₹$ en forma que lo balen muy bien y asi lo declaramos y firmamos de muy ... fe en Madrid a 4 dias del mes de noviembre de 1612 y advirtiendo que este precio se entiende a bien de lo dado molduras y lienzos.

\section{A. PereZ De GuZman $\quad$ ANDres LopeZ}

